Brazilian Journal

of Chemical

Engineering

ISSN 0104-6632

Printed in Brazil

Vol. 19, No. 02, pp. 141 - 150, April - June 2002

\title{
DEVELOPMENT AND CHARACTERIZATION OF MICROFILTRATION HOLLOW-FIBER MODULES FOR STERILIZATION OF FERMENTATION MEDIA
}

\author{
L.F.F.Faria $^{1^{*}}$, M.Di Luccio ${ }^{2 *}$, R.Nobrega ${ }^{3}$ and C.P.Borges ${ }^{3}$ \\ ${ }^{1}$ Departamento de Engenharia Química, Faculdade de Engenharia Química de Lorena, \\ Rod. Itajubá-Lorena km 74,5, 12600-000, Lorena - SP, Brazil; \\ E-mail: figueiredo@dequi.faenquil.br \\ ${ }^{2}$ Departamento de Engenharia de Alimentos, URI, Campus de Erechim, Phone: +55 (54)520-9000, \\ Fax: +55 (54) 520-909099700-000, Erechim - RS, Brazil. \\ E-mail: diluccio@uricer.edu.br \\ ${ }^{3}$ Programa de Engenharia Química, COPPE/UFRJ, Centro de Tecnologia, \\ Bloco G, S. 115, 21945-970, Rio de Janeiro - RJ, Brazil.
}

(Received: February 10, 2002 ; Accepted: April 17, 2002)

\begin{abstract}
Sterilization of fermentation medium involving heat may result in undesirable chemical reactions that alter nutrient concentration and yield products, which interfere in the fermentation performance. Sterilization of heat-sensitive compounds usually involves separate sterilizations of carbon source and nutrient solution. Membrane separation processes are an alternative to thermal processes, as they have many advantages such as the possibility of continuous and modular operation and the use of moderate temperatures. In this context, the objective of this work was the preparation of hollow-fiber membranes and the design of modules suitable for continuous sterilization of fermentation medium. The membrane with the best performance had a maximum pore diameter of $0.2 \mu \mathrm{m}$ and a permeability of $42.9 \mathrm{~L} / \mathrm{m}^{2}$.bar.h for a glucose/peptone/yeast extract medium. A module with $0.26 \mathrm{~m}^{2}$ of permeation area was built with these membranes. This module was able to provide a permeate flow rate of $2.2 \mathrm{~L} / \mathrm{h}$ using a pressure difference of 0.2 bar. The collected permeate was completely sterile, thus confirming the efficiency of this process.
\end{abstract}

Keywords: sterilization, membrane processes, microfiltration, fermentation.

\section{INTRODUCTION}

Membrane separation technology has been largely used in many steps of bioprocesses, such as the sterilization of fermentation media. Conventionally, this step is carried out using thermal processes. In this case, temperatures above $100^{\circ} \mathrm{C}$ are necessary in order to destroy bacterial spores. Nevertheless, vitamins, antibiotics and many sugars degrade when submitted to high temperatures, altering medium composition. The only alternative capable of overcoming this problem is sterilization through mechanical removal of microorganisms, such as in filtration (Crueger and Crueger, 1989; Cheryan, 1998).

Membrane processes have many advantages, such as their high selectivity and low energy demand, since they do not require high temperatures to perform separation. Besides, these processes do not demand changes in $\mathrm{pH}$ or use of chemical solvents, they can be operated continuously and they are modular processes, which makes them very simple to operate (Noble and Stern, 1995; Baker et al., 1991). Microfiltration membranes are used to remove

*To whom correspondence should be addressed 
particles (with diameters between 0.1 and $0.5 \mu \mathrm{m}$ ) from suspensions. Considering that the minimum diameter of one of the smallest known microorganisms is about $0.2 \mu \mathrm{m}$ (Pseudomonas diminuta) (Castelas et al., 1996), this process is suitable for sterilization of thermosensitive medium. Flat sheet and hollow fiber are the most common membrane geometries. The latter has more advantages than flat-sheet membranes, because they have a higher permeation area/module volume ratio. Another advantage of hollow fibers is that they are self-supporting, i.e., they do not require a support or spacers to separate membranes.

The objective of this work was the preparation of microporous hollow-fiber membranes and the development of permeation modules suitable for continuous sterilization of fermentation medium. Membranes were prepared using phase inversion process by means of immersion precipitation. This technique consists in inducing instability in a polymer solution, initially thermodynamically stable, by immersion of a thin film of the solution into a precipitation bath containing a nonsolvent for the polymer. Immediately after immersion, the inflow of nonsolvent into the polymer solution and the outflow of solvent out of the solution take place. Mass transfer in the polymer film may induce many phenomena, such as the nucleation and growth of a new phase, poor in polymer, dispersed in a polymerrich phase.

This proceeds until the viscous effects characteristic of the polymer system (glass transition, gelation and crystallization) take place, fixing the membrane structure. The polymer-lean phase will then form the membrane pores, while the polymerrich phase will form the membrane matrix. Depending on the composition of the polymer solution and the precipitation bath, different membranes suitable for different applications can be obtained. In hollow-fiber formation, many other parameters can affect membrane morphology and final properties of the membrane, such as the distance between the spinneret and the precipitation bath (air gap), temperature of the precipitation bath, flow rate of the polymer solution and composition and flow rate of the bore liquid (Borges, 1993; Di Luccio, 1997).

\section{EXPERIMENTAL}

\section{Materials}

Polyetehrimide was used as base polymer (PEI ULTEM $^{\circledR} / \mathrm{GE}$ ), N-methyl-2-pyrrolidone (NMP, Aldrich) as solvent, polyvinylpyrrolidone (PVP Aldrich, Mw $360 \mathrm{kDa}$ ) as additive and filtered water as nonsolvent. The polymer solution contained 17 wt $\%$ PEI, $7 \mathrm{wt} \%$ PVP and $76 \mathrm{wt} \%$ NMP, based on the work of Borges (1993). PEI was chosen as base polymer due to its excellent thermal and chemical resistance.

\section{Methods}

Hollow-fiber spinning was carried out in a pilot system, varying precipitation bath (external liquid) temperature and the distance between the spinneret and the precipitation bath (air gap). Spinning conditions are listed in Table 1.

After spinning, the fibers were washed with distilled water and kept at $60^{\circ} \mathrm{C}$ for $24 \mathrm{~h}$ for complete elimination of residual solvent. They were then dried at room temperature after solvent replacement (ethanol and n-hexane). This procedure was used with the intention of avoiding morphological changes in the membranes due to the high surface tension of water. After drying, samples for each spinning condition were analyzed by Scanning Electron Microscopy (SEM).

Table 1: Hollow-fiber spinning conditions

\begin{tabular}{|c|c|c|c|}
\hline $\begin{array}{c}\text { Fiber spinning } \\
\text { condition }\end{array}$ & $\begin{array}{c}\text { Precipitation bath } \\
\text { temperature }\left({ }^{\circ} \mathbf{C}\right)\end{array}$ & Air gap (cm) & $\begin{array}{c}\text { Polymer solution } \\
\text { flow rate (g/min) }\end{array}$ \\
\hline PEI-A & 30 & 9 & 1.8 \\
\hline PEI-B & 30 & 3 & 1.8 \\
\hline PEI-C & 30 & 1 & 1.8 \\
\hline PEI-D & 50 & 1 & 1.8 \\
\hline PEI-E & 50 & 9 & 1.8 \\
\hline PEI-F & 30 & 3 & 3.6 \\
\hline PEI-G & 30 & 1 & 3.6 \\
\hline
\end{tabular}

" precipitation bath $100 \mathrm{wt} \% \mathrm{H}_{2} \mathrm{O}$ and bore liquid $10 \mathrm{wt} \% \mathrm{NMP}$ and $90 \mathrm{wt} \% \mathrm{H}_{2} \mathrm{O}$

Membranes that had maximum pore diameters less than or equal to $0.20 \mu \mathrm{m}$ were characterized by gas $\left(\mathrm{N}_{2}\right)$ and water permeability. For water permeability tests, borosilicate glass modules $(2.5$ $\mathrm{cm}$ diameter $\times 25 \mathrm{~cm}$ length), containing eight fibers each, were built 
Water permeability was tested before and after autoclaving to discard possible alterations in membrane morphology and properties due to thermal sterilization. Based on microscopy and permeability results, two different membranes were chosen for sterilization performance tests. These tests consisted in feeding the modules with a glucose medium (10 $\mathrm{g} / \mathrm{L}$ glucose, $10 \mathrm{~g} / \mathrm{L}$ peptone, $3 \mathrm{~g} / \mathrm{L}$ yeast extract, 1 $\mathrm{g} / \mathrm{L}$ potassium phosphate and $5 \mathrm{~g} / \mathrm{L}$ sodium chloride) inoculated with Escherichia coli and Saccharomyces cerevisiae cells previously grown on the same medium. Permeate was collected aseptically and samples $(0.1 \mathrm{~mL})$ were added to tubes containing thioglycollate medium $(29.5 \mathrm{~g} / \mathrm{L} \quad$ Merck thioglycollate medium base in distilled water, $\mathrm{pH} 7$ ). These tubes were incubated at $37^{\circ} \mathrm{C}$ for $48 \mathrm{~h}$ and inspected visually.

After the sterilization performance tests, the chosen membranes were used in manufacture of a larger scale module, able to provide higher permeate flow rates. This module was built using a borosilicate glass tube with $3.5 \mathrm{~cm}$ diameter and 40 $\mathrm{cm}$ length, housing 232 fibers. The module was tested following the procedures described above and it was used in a fermentation system.

\section{RESULTS AND DISCUSSION}

In the sterilization using hollow-fiber membranes, feed was flowed through the external side of the fibers and permeate was collected from the inside of the fibers. Therefore, the external surface was the selective layer for the medium containing contaminants. The first step in the choice of the best fiber, which met the objectives of this work, consisted in visual inspection of the external and internal fiber surface by Scanning Electron Microscopy (SEM). Figure 1 shows a typical cross section of the fibers obtained in this work. The morphologies of the cross sections of all studied fibers were very similar. All of them showed high pore interconnectivity and similar porosity.

Figure 2 shows the influence of the precipitation bath temperature and air gap on fiber morphology. Association of these two parameters markedly influences surface characteristics of the membrane. The gap between the spinneret and the precipitation bath determines the exposure time of the fiber before it reaches the precipitation bath. This exposure time is an important parameter, which significantly influences final membrane morphology, since it is directly related to water vapor absorption by the polymer solution, since both the solvent (NMP) and the additive (PVP) are hygroscopic.

When the precipitation bath temperature increases, the amount of vapor present in the gap also increases, favoring water absorption by the polymer solution that just left the spinneret. The absorption of water may induce the nucleation and growth of the polymer-poor phase process, even before the fiber reaches the precipitation bath. During this time interval, there is practically no outflow of solvent from the polymer solution due to its low volatility. Instead, there is only the inflow of nonsolvent, which may lead to dilution of the polymer solution that will precipitate from a lower concentration of polymer.

These two facts contribute to the increase of pore diameter on external surface of the fiber (Figure 2(a), PEI-C and PEI-D). In the same way, the larger the air gap, the longer the residence time of the polymer solution film outside the precipitation bath. This fact allows the precipitation diffusion front, caused by the mass transfer between the bore liquid and the polymer solution, to reach the external layers of the fiber, causing the composition of these layers to change and favoring the nucleation and growth of polymer-poor phase and, consequently, an increase in pore diameter in those layers (Figure 2 (b) PEI-F and PEI-G).

The spinning conditions using the lower polymer solution flow rate resulted in thin wall fibers (Figure 3), which leads to a lower mechanical resistance. For this reason, the fibers PEI-A to PEI-E were discarded.

Table 2 shows the permeability results for fibers PEI-F and PEI-G. The water permeabilities were obtained before module autoclaving. The permeability of a fermentation medium containing glucose, yeast extract and salts in the same concentration as that used in the fermentations carried out by the group is also presented in this table. It is worth observing that fiber PEI-G had much lower water permeability than fiber PEI-F. This result agrees with the observations on the external surface morphology of the fiber, which showed that fiber $\mathrm{G}$ did not have any visible pores when analyzed at the same magnification as fiber $\mathrm{F}$. The decrease in pore diameter is due to the decrease in the gap between the spinneret and the precipitation bath, as discussed above. Fiber $G$ was discarded because of its low water permeability.

The data in Table 2 also show that permeability drops about $60 \%$ when a real fermentation medium is used in the feed. This behavior is expected and is probably due to the increase in feed viscosity, which is inversely proportional to permeability, as well as 
to the membrane fouling. This phenomenon is already well known and has been studied by other authors (Castelas et al., 1996; Borges, 1993). Membrane fouling is normally related to pore blocking with particulate species and to adsorption of protein and other compounds present in the feed onto membrane pores, decreasing the effective pore diameter and, consequently, membrane permeability. Therefore, for the dimensioning of a microfiltration module that will be used in a medium sterilization continuous system, it is necessary to consider the decrease in permeability caused by many factors, such as fouling.

Many methods may be used for asepsis of hollow-fiber modules. In this work, sterilization using humid heat was chosen due to the availability of the necessary equipment in the lab. Therefore, any changes in fiber characteristics resulting from the heating cycles should also be taken into account. Water permeability was measured before and after autoclaving the modules at $121^{\circ} \mathrm{C}$ for 20 minutes. A decrease in water permeability lower than $20 \%$ of the original value was then observed, even after many sterilization cycles. This result confirms that the asepsis method used does not considerably alter fiber characteristics, as expected, since the base polymer has an excellent thermal resistance.
The fiber obtained using condition ${ }^{7}$ was selected for having the best performance for sterilization purposes. A module assembled with these fibers was submitted to the sterilization performance tests, using glucose medium inoculated with bacteria and yeast cells. The permeate was collected aseptically and samples were inoculated in tubes with previously sterilized thioglycollate medium and incubated at $37^{\circ} \mathrm{C}$. Figure 4 shows the results obtained after $48 \mathrm{~h}$ of incubation. Tube A corresponds to the control, which was inoculated with a sample of the feed suspension, while the others were inoculated with the permeate obtained after 30, 60 and 90 minutes, respectively. No microbial growth was observed in the tubes inoculated with the permeate, showing the efficiency of the module in sterilizing fermentation media. None of the tubes showed any growth, even after one week of incubation.

After the sterilization performance tests, the same fiber was used to manufacture a larger module, made of borosilicate glass tube with a diameter of $3.5 \mathrm{~cm}$ and a length of $40 \mathrm{~cm}$, housing 232 fibers (Figure 5). This module was also submitted to the sterilization performance test, reproducing previous results. The total permeation area of this module was $0.26 \mathrm{~m}^{2}$, assembled in a volume of $3.5 \times 10^{-4} \mathrm{~cm}^{2}$, which corresponds to an area/volume ratio of $743 \mathrm{~m}^{2} / \mathrm{m}^{3}$. This ratio is much higher than that obtained for flatsheet membranes on lab scale, which is around 12 $\mathrm{m}^{2} / \mathrm{m}^{3}$. This module yielded a permeate flow rate of $11 \mathrm{~L} / \mathrm{h}$ at a pressure difference of 1 bar.

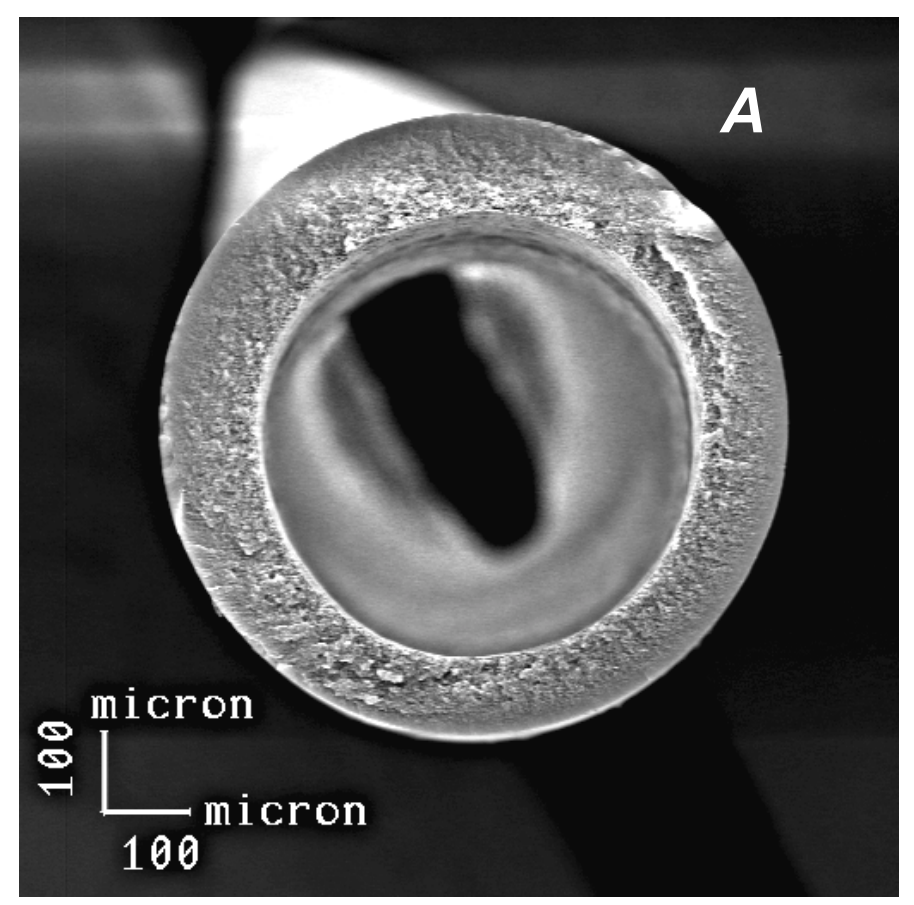

(A) 


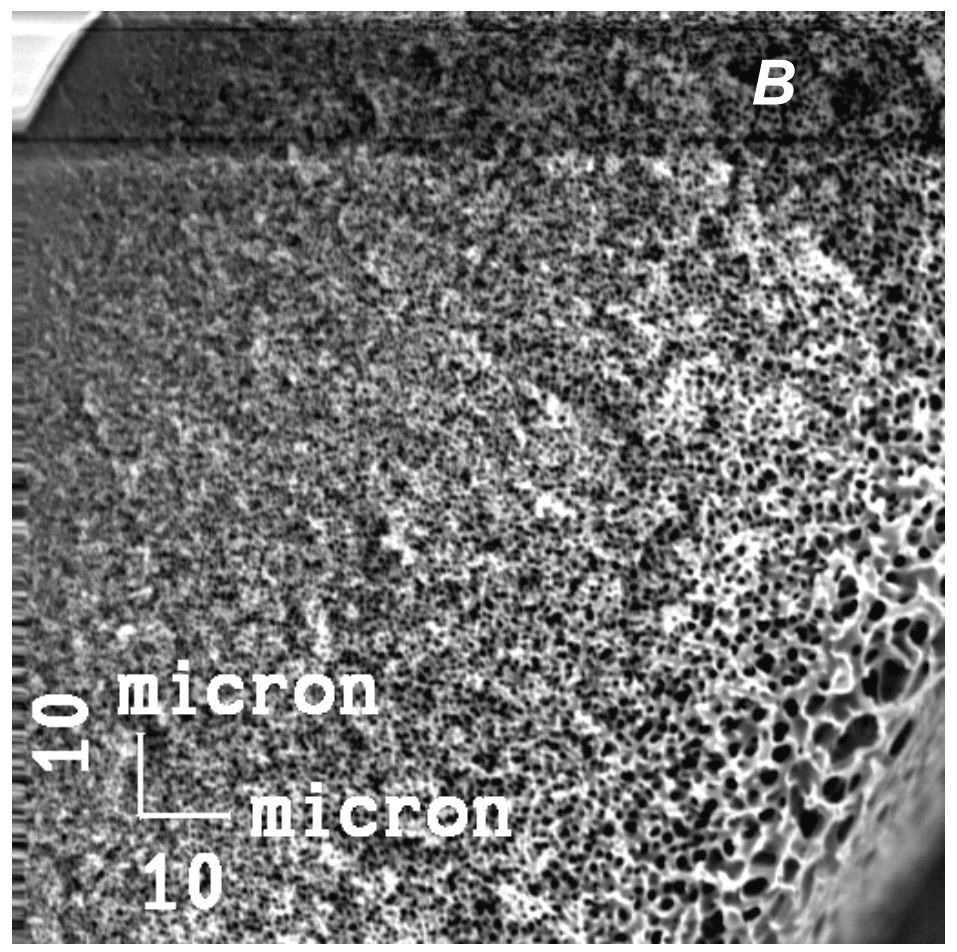

(B)

Figure 1: Cross section of PEI-F condition. A - global view; B - higher magnification.

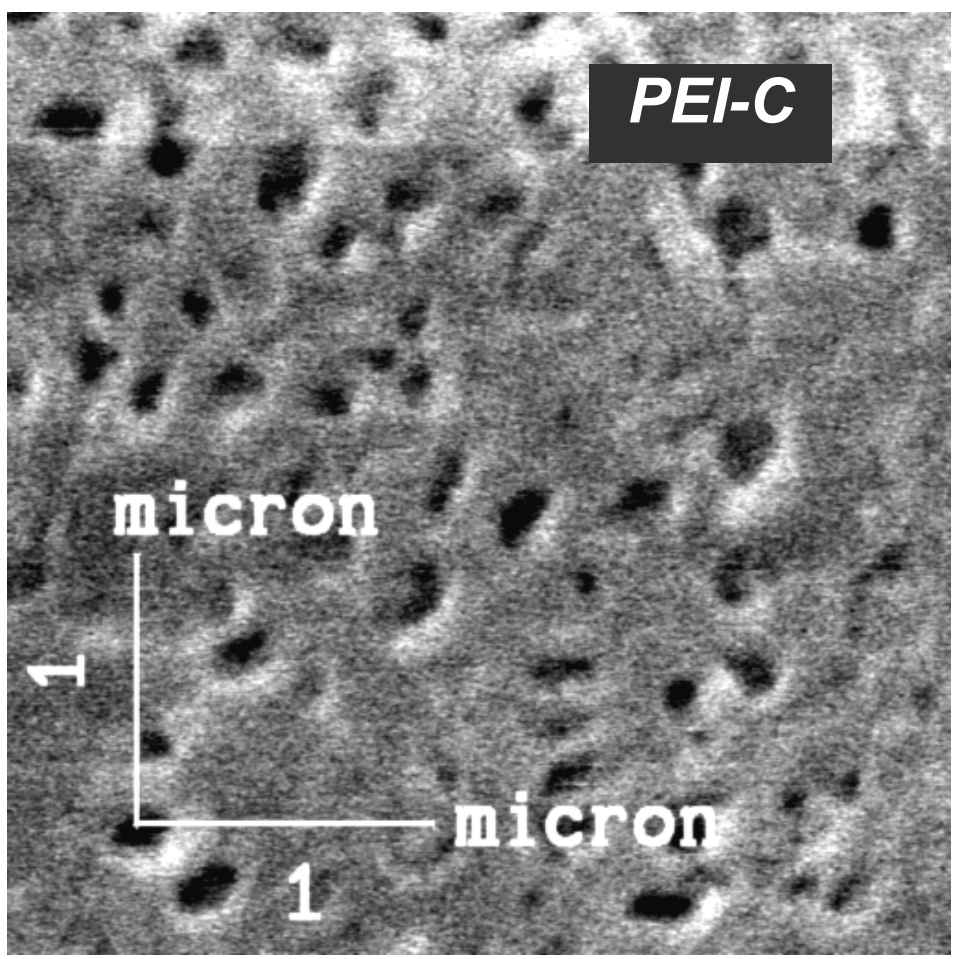




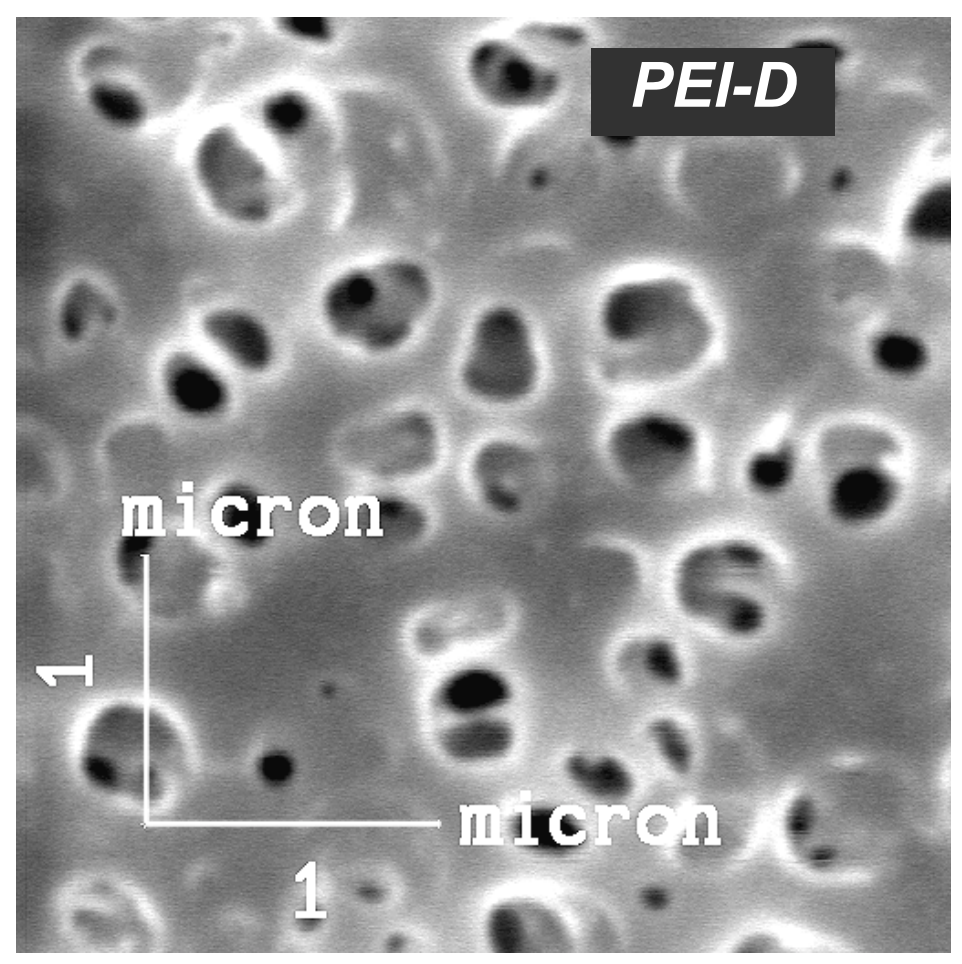

Figure 2(a): Effect of precipitation bath temperature on external surface morphology. PEI-C $-\mathrm{T}_{\text {bath }}=30^{\circ} \mathrm{C}$, gap $=1 \mathrm{~cm}$, PEI-D $-\mathrm{T}_{\text {bath }}=50^{\circ} \mathrm{C}$, gap $=1 \mathrm{~cm}$.

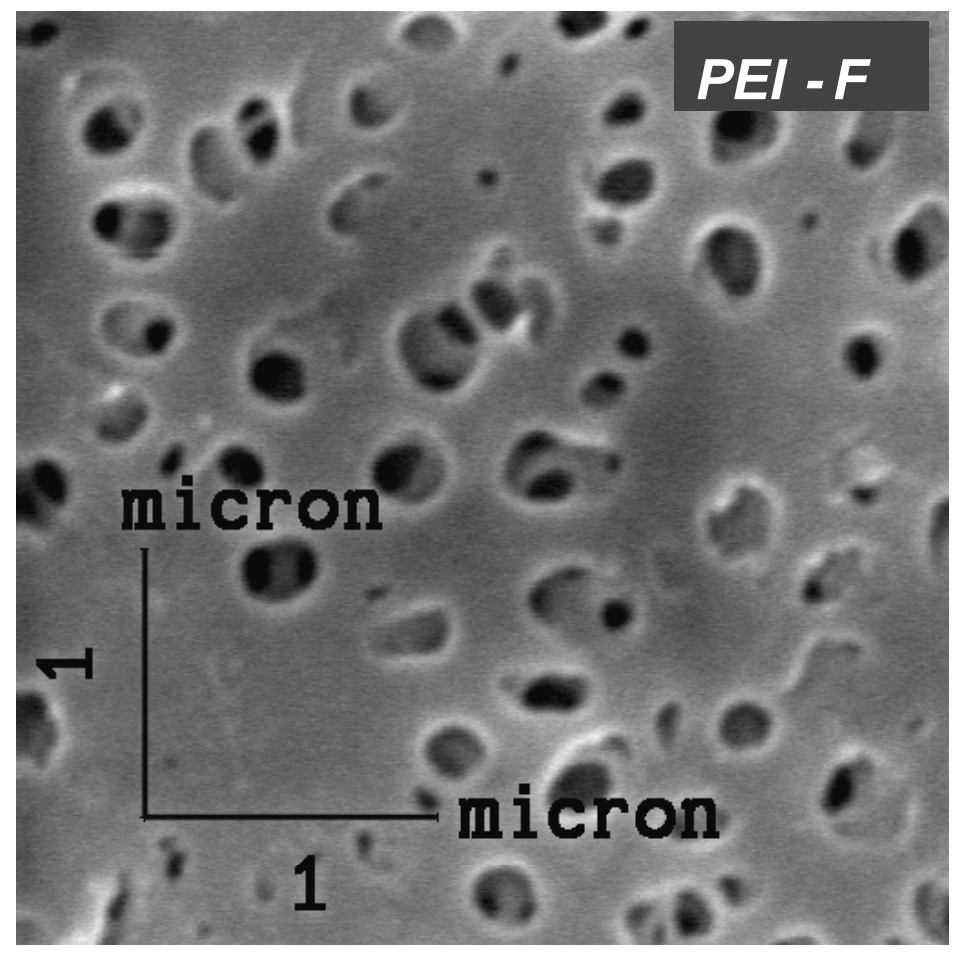




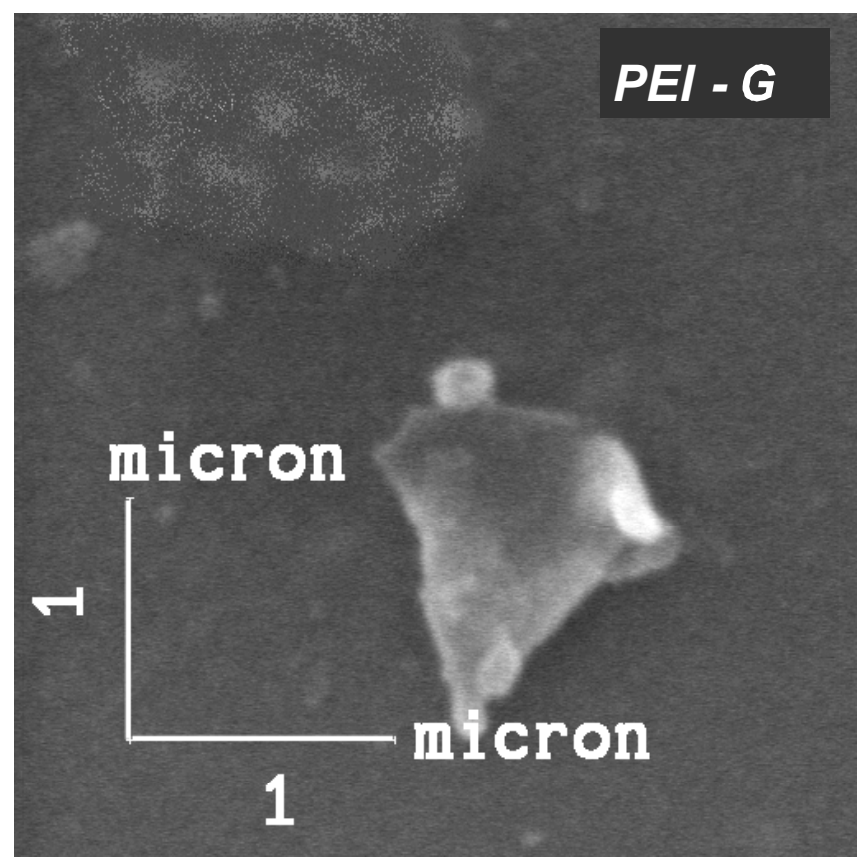

Figure 2(b): Effect of air gap on external surface morphology. PEI-F $-\mathrm{T}_{\text {bath }}=30^{\circ} \mathrm{C}$, gap $=3 \mathrm{~cm}$, PEI-G $-\mathrm{T}_{\text {bath }}=30^{\circ} \mathrm{C}$, gap $=1 \mathrm{~cm}$.

Table 2: Permeability results

\begin{tabular}{|c|c|c|c|}
\hline $\begin{array}{c}\text { Fiber spinning } \\
\text { condition }\end{array}$ & $\begin{array}{c}\text { Water permeability } \\
\left(\mathbf{L} / \mathbf{m}^{\mathbf{2}} \text {.h.bar }\right)\end{array}$ & $\begin{array}{c}\text { Nitrogen permeability } \\
\left(\mathbf{c m}^{\mathbf{3}} / \mathbf{c m}^{\mathbf{2}} \mathbf{. c m H g . s}\right)\end{array}$ & $\begin{array}{c}\text { Fermentation medium } \\
\left.\text { permeability (L/. } \mathbf{m}^{\mathbf{2}} \mathbf{. h} . \mathbf{b a r}\right)\end{array}$ \\
\hline PEI-F & 115.5 & 0.02 & 42.9 \\
\hline PEI-G & 68.4 & 0.02 & - \\
\hline
\end{tabular}

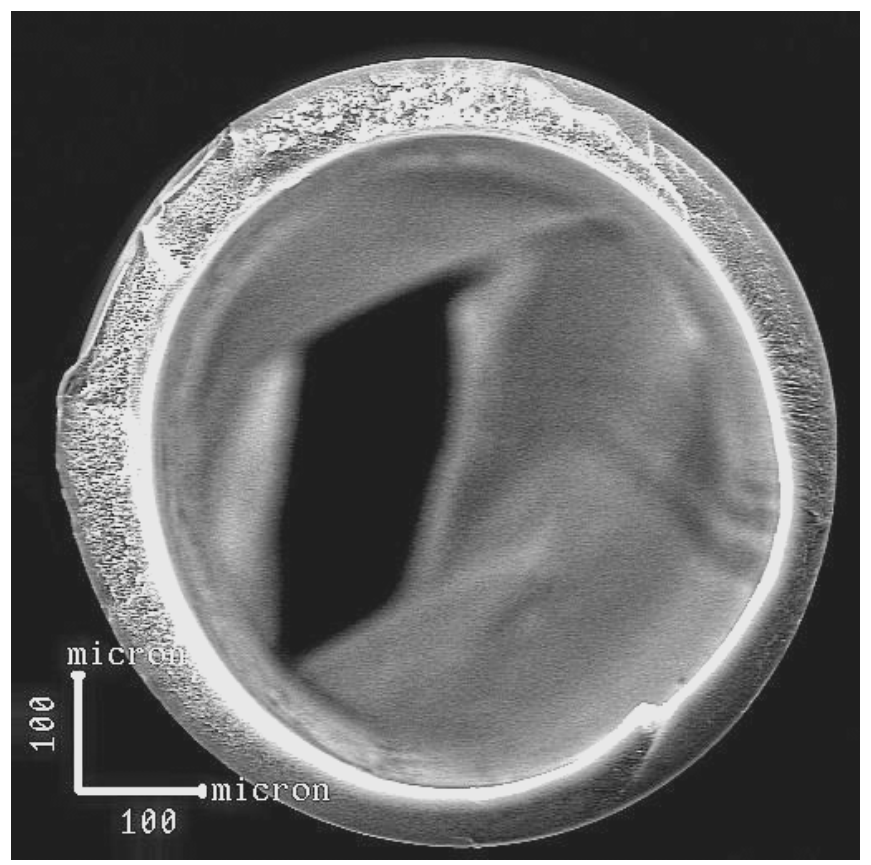




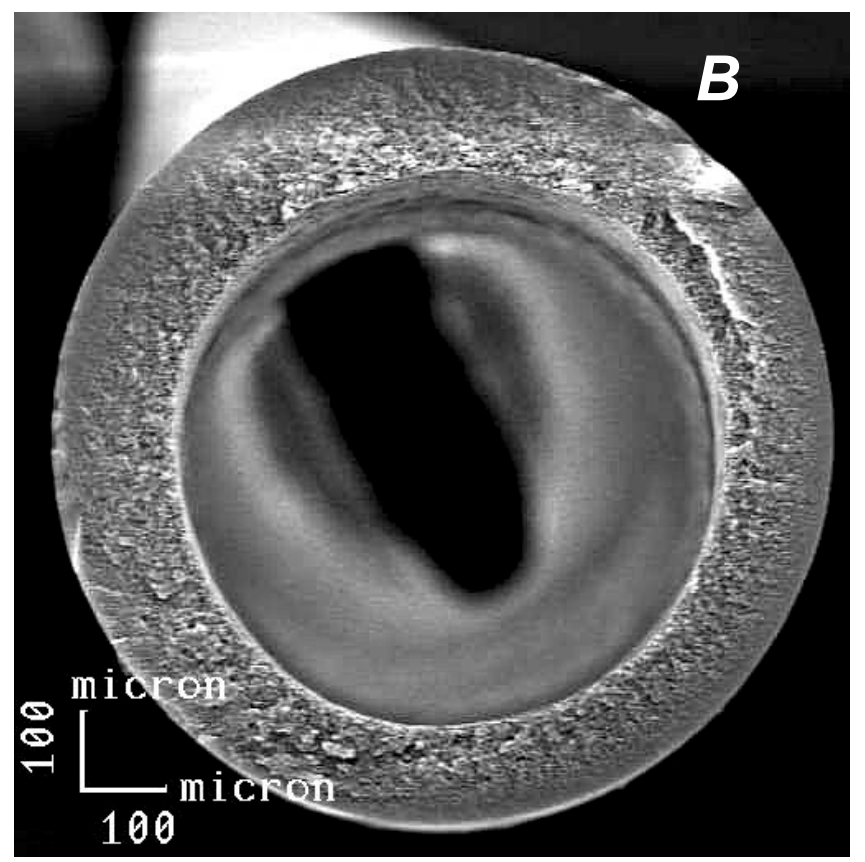

Figure 3: (A) cross section PEI-C, polymer solution flow rate: $1.8 \mathrm{~g} / \mathrm{min}$; (B) cross section PEI-F, polymer solution flow rate: $3.6 \mathrm{~g} / \mathrm{min}$.

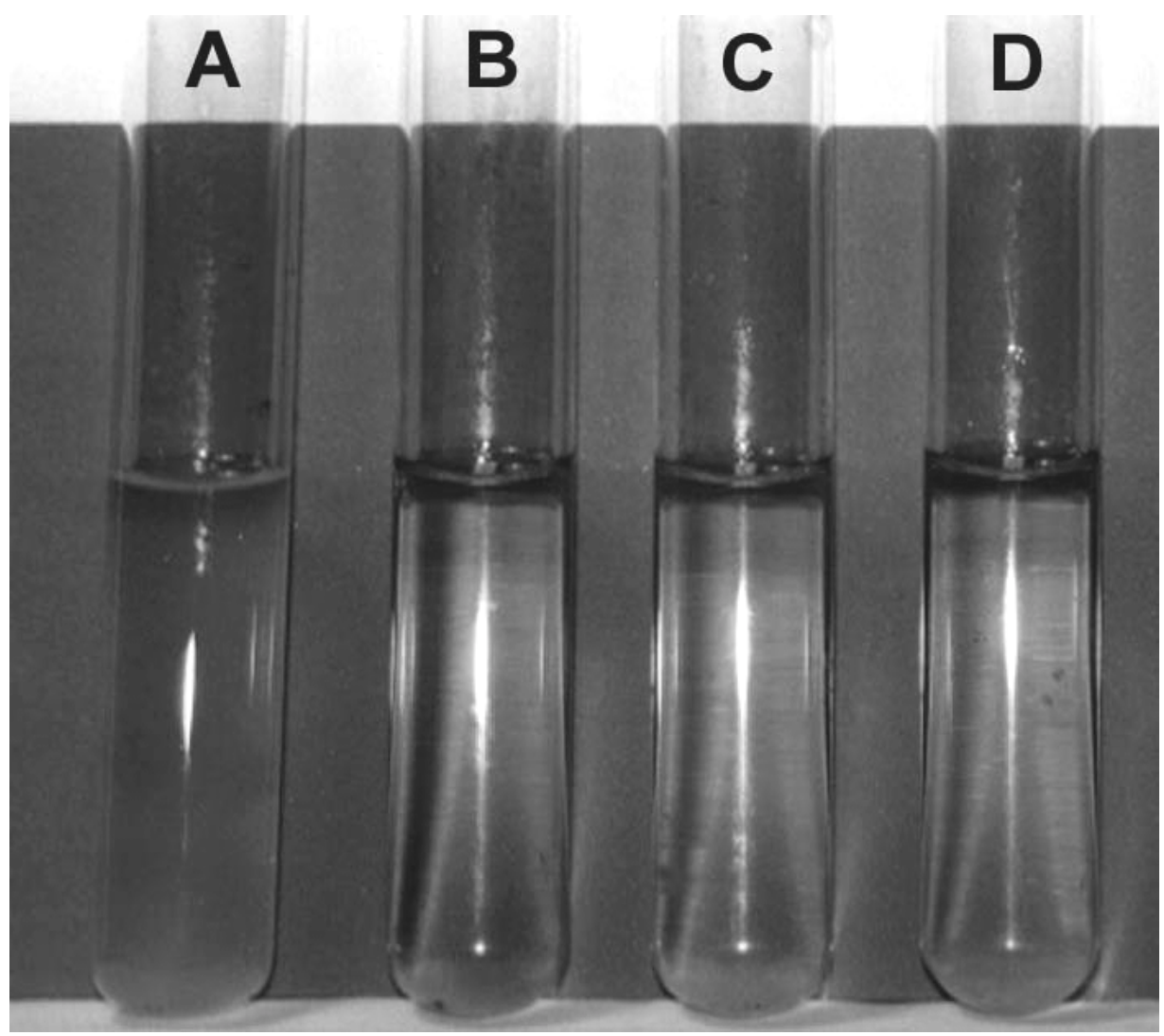

Figure 4: Results of sterilization performance test. Tube A - control; B, C, D - permeates. 


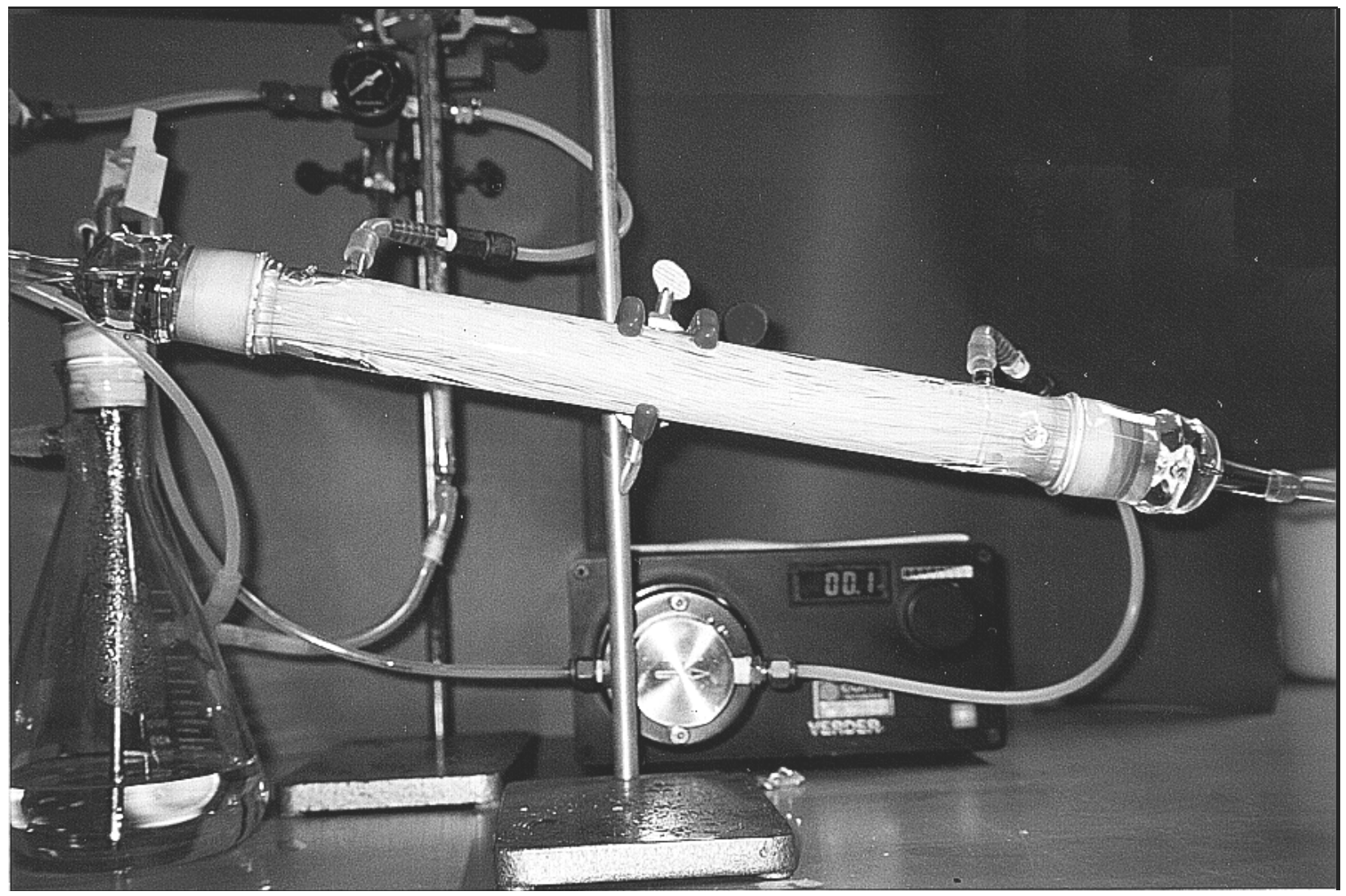

Figure 5: Hollow-fiber membrane module for continuous sterilization of fermentation medium.

\section{CONCLUSIONS}

This work shows that microporous hollow-fiber membranes can be successfully used in the sterilization of fermentation media. The balanced adjustment of spinning parameters results in the obtaining of highly efficient fibers with satisfactory permeate fluxes for sterilization applications. Characterization of the microfiltration module using real fermentation media is extremely important for module design. Sterilization of fermentation medium using microfiltration hollow-fiber membranes is therefore an extremely feasible and practical alternative. It is easy to operate and also results in an increase in process productivity because it favors continuous operation for long periods and scale changes by simply adding or removing permeation modules.

\section{ACKNOWLEDGEMENTS}

The authors would like to thank Prof. Selma G. F. Leite for her valuable contributions to the sterilization performance tests. The financial support received from $\mathrm{CNPq}$, FAPERJ and CAPES is also acknowledged.

\section{REFERENCES}

Baker, R.W., Cussler, E.L., Eykamp, W., Koros, W.J., Riley, R.L. and Strathmann, H., Membrane Separation Systems - Recent Developments and Future Directions, Ed. Noyes Data Corporation, New Jersey (1991).

Borges, C.P., Fibras-ocas Compostas para Remoção de Poluentes Orgânicos de Soluções Aquosas pelo Processo de Pervaporação. Ph.D. diss., COPPE./UFRJ, Rio de Janeiro, Brazil (1993).

Castelas, B., Huitorel, L. and Cueille, G., Membrane Technologies in Water Treatment and Environmental Protection, Filtration \& Separation, 459-462 (1996).

Cheryan, M., Ultrafiltration and Microfiltration Handbook, Technology Publishing Co., NY, USA (1998).

Crueger, W. and Crueger, A. Biotechnology: A Textbook of Industrial Microbiology, $2^{\text {nd }}$ 
ed., Science Tech Publishers, NY, USA (1989).

Di Luccio, M., Membranas Microporosas Planas e do Tipo Fibra-oca a Partir de Sistemas Contendo Policarbonato como Polímero Base, Master's thesis, COPPE./UFRJ, Rio de Janeiro, Brazil (1997).

Noble, R.D. and Stern, S.A., Membrane Separations Technology, Principles and Applications, Elsevier Science, NY, USA (1995). 